\title{
REAL ECONOMY: TRENDS AND FACTORS IN APRIL 2013
}

\author{
O.Izryadnova
}

The slowdown of the economic growth in April 2013 was determined by the slackening of the investment demand dynamics. In April 2013 the investments in fixed assets made 99.3\%, in January-April-99.8\% of the corresponding indices of the previous year. However, the indices of the industrial production in March-April 2013 in annual terms demonstrate some growth after the recession of January-February. The growth rates of the industrial production this April in annual terms made $2.3 \%$.

According to the preliminary estimation of the Federal State Statistics Service, in Q1 2013 the growth of the GDP made $1.6 \%$ in annual terms as compared with $4.8 \%$ in the corresponding period of the previous year. The slowdown of the economic growth was determined by the simultaneous decrease in the demand at the internal and the external markets. Starting with Q2 2012 the absolute volumes of the Russian export have been observed to contract in terms of value. As a result during the last three quarters of 2012 and Q1 2013 the positive trade balance has been decreasing.

Starting with December 2012 the internal market has been considerably influenced by the decrease in the investments in fixed assets. In April 2013 the investments in fixed assets made 99.3\% and in January-April 99.8\% of the corresponding figures of the previous year.

In Q1 2013 the trends towards the contraction of the public investments formed in 2012 was maintained. The diminishing of the public investments was accompanied by the decrease in the activity of the major infrastructure companies in connection with the finishing of several investment projects and corrections in the plans taking into account the changes in the situation at the market. The contraction of the incomes of the enterprises has intensified the trend towards the investments in fixed assets decrease in January-April 2013. The decrease in the investment activity in the investment sector is also connected with the intensification of the capital outflow in Q1 of the current year up to USD 25.8bn versus USD 7.9bn in Q4 2012 ${ }^{1}$. In contrast to Q1 2012 in 2013 the capital outflow was practically completely accounted for by the export of the banking capital, which weakened considerably the participation of the banks in the financing of the investments in the fixed assets in the Russian economy.

Table 1 NET IMPORT/EXPORT OF THE CAPITAL BY THE PRIVATE SECTOR IN 2012 AND IN Q1 2013, AS USD BILLION

\begin{tabular}{l|c|c|c|}
\hline & $\begin{array}{c}\text { Net capital import/export } \\
\text { by the private sector }\end{array}$ & $\begin{array}{c}\text { Net import/export } \\
\text { by the banks }\end{array}$ & $\begin{array}{c}\text { Net import/export } \\
\text { by other sectors }\end{array}$ \\
\hline 2012 & -54.1 & 18.5 & -72.7 \\
\hline Q1 & -33.6 & -9.7 & -23.8 \\
\hline Q2 & -5.3 & 11.6 & -16.9 \\
\hline Q3 & -7.4 & 7.7 & -15.1 \\
\hline Q4 & -7.9 & 8.9 & -16.9 \\
\hline 2013. & & & -1.8 \\
\hline Q1 (estimation) & -25.8 & -24 & \\
\hline
\end{tabular}

Source: RF Central Bank.

As compared with the corresponding period of the previous year in Q1 2013 the inflow of the foreign investments in the Russian economy went up by 1.65 times, the direct foreign investments making $\$ 6.3 \mathrm{bn}$. In contrast to the previous year in Q1 2013 the growth of the direct invest-

1 It should be noted that according to the forecast of the RF Ministry of Economic Development the net capital outflow is estimated to be at the level of $\$ 30 \mathrm{bn}$. 
ments was due to the sharp increase in the volume of credits received from the foreign co-owners of the organizations, the proportion of the investments in the capital contracting.

Starting with the H2 2013 the situation in the Russian economy was complicated with the sharp slowdown of the consumer demand. In April 2013 the annual growth rates of the retail trade turnover made $4.1 \%$ versus $7.1 \%$ a year ago and the rates of the paid services rendered to the population $-1.7 \%$ versus $3.5 \%$, correspondingly. It was the level of inflation and the real incomes of the population that have affected the consumer behavior. As compared with the corresponding period of the previous year, in April 2013 the consumer prices index went up to 107.2\% versus $103.6 \%$ a year ago. The growth rates of the real wages slowed down to $104.2 \%$ in April 2013 versus $111.1 \%$ in the corresponding period of the previous year. In spite of the fact that as a result of pensions and other types of social payments indexation the real disposable monetary incomes of the population went up by $7.3 \%$ in April 2013 (in annual terms), this has not influenced the dynamics of the retail trade turnover. Besides, it was the decrease in the growth rates of credits issuing to the population observed since August 2012 was a factor contributing to the weakening of the consumer activity of the population.

Table 2

INFLOW OF FOREIGN INVESTMENTS IN Q1 2010-2013, AS BROKEN BY TYPES

\begin{tabular}{l|c|c|c|c|c|c|c|c|c|} 
& \multicolumn{3}{|c|}{ USD million } & \multicolumn{3}{c|}{$\begin{array}{c}\text { As percentage } \\
\text { to the total }\end{array}$} & \multicolumn{2}{c|}{$\begin{array}{c}\text { As percentage on the corresponding } \\
\text { period of the previous year }\end{array}$} \\
\cline { 2 - 12 } & 2011 & 2012 & 2013 & 2011 & 2012 & 2013 & 2011 & 2012 & 2013 \\
\hline $\begin{array}{l}\text { Investments } \\
\text { of which: }\end{array}$ & 44349 & 36534 & 60436 & 100 & 100 & 100 & 340.0 & 82.4 & 165.4 \\
\hline $\begin{array}{l}\text { direct } \\
\text { portfolio }\end{array}$ & 3890 & 3863 & 6304 & 8.8 & 10.6 & 10.4 & 148.3 & 99.3 & 163.2 \\
\hline other & 122 & 1007 & 119 & 0.3 & 2.8 & 0.2 & 41.8 & 820.0 & 11.8 \\
\hline
\end{tabular}

Source: Federal State Statistics Service.

Table 3

GROWTH RATES OF THE MAIN ECONOMIC INDICES IN APRIL 2008-2013, AS PERCENTAGE TO THE CORRESPONDING PERIOD OF THE PREVIOUS YEAR

\begin{tabular}{|l|c|c|c|c|c|c|}
\hline & 2008 & 2009 & 2010 & 2011 & 2012 & 2013 \\
\hline Output volume by basic types of economic activities & 109.6 & 85.1 & 107.7 & 103.3 & 103.9 & $102.0^{*}$ \\
\hline Industry & 105.7 & 85.8 & 110.4 & 104.5 & 101.3 & 102.3 \\
\hline Minerals extraction & 102.7 & 97.3 & 104.6 & 101.4 & 101.5 & 102.6 \\
\hline Manufacturing industries & 108.8 & 77.6 & 116.5 & 105.3 & 103.6 & 101.2 \\
\hline Investments in fixed assets & 125.0 & 80.4 & 101.7 & 102.2 & 107.8 & 99.3 \\
\hline Workload in construction & 121.8 & 86.5 & 94.5 & 98.1 & 103.8 & 96.3 \\
\hline Retail trade turnover & 114.9 & 95.6 & 105.9 & 105.5 & 107.0 & 104.1 \\
\hline of foodstuffs & 108.4 & 101.7 & 104.8 & 101.0 & 104.6 & 101.6 \\
\hline of non-food goods & 120.4 & 90.2 & 106.9 & 110.1 & 109.0 & 106.2 \\
\hline Volume of paid services & 107.2 & 96.2 & 100.7 & 104.1 & 103.5 & 101.7 \\
\hline Foreign trade turnover & 149.5 & 54.5 & 147.2 & 138.6 & 98.6 & $100.0^{*}$ \\
\hline Export & 148.0 & 52.3 & 149.2 & 137.0 & 98.3 & $95.2^{*}$ \\
\hline Import & 152.0 & 58.0 & 130.1 & 141.5 & 99.2 & $108.1^{*}$ \\
\hline Real disposable incomes of the population & 109.1 & 102.4 & 105.7 & 98.1 & 101.3 & 107.3 \\
\hline Real accrued wages & 114.6 & 95.7 & 105.9 & 102.4 & 111.1 & 104.2 \\
\hline Total number of the unemployed & 94.4 & 148.6 & 91.8 & 88.1 & 79.3 & 99.4 \\
\hline
\end{tabular}

* preliminary data

Source: Federal State Statistics Service.

This year the industrial production is characterized by a highly unsteady dynamics. The decrease in the volumes of the industrial production in January-February 2013 by $1.8 \%$ versus the corresponding period of 2012 was replaced by the recovery of the of the industrial growth in the following two months, which resulted in stabilization of the output approximately at the level of 
January-April 2012. This April the growth of the industrial production In annual terms made $102.3 \%$, the figures being $102.6 \%$ in minerals extraction, $101.2 \%$ in manufacturing industries, $102.8 \%$ - in electricity, gas and water production and distribution. The manufacturing industry is no longer the driving force of the industrial development. Besides, in this sector of the economy the differentiation of the development rates by the types of the economic activities has become more pronounced.

Starting with December 2012 the contraction of the production in machine-building complex negatively influences the dynamics of the manufacturing industries. In April 2013 as compared with the corresponding period of the previous year in machine-building complex machinery and equipment production index made $98.5 \%$, electric, electronic and optic equipment production index - 96.0\%. In April 2013 the production of the transport vehicles and equipment went up by $4.0 \%$ on April 2012 figure, but on the whole over January-April the production made 97.5\% of the corresponding figure of the previous year.

The RF Ministry of Economic Development has published the forecast for the scenario conditions of the socio-economic development in 2014 and in the planning period of 2015-2016, prepared on the basis of the single hypothesis of the external conditions and different variants of the government policy and private sector development ${ }^{1}$.

It is the moderately optimistic variant (2) that is suggested as the basis for the elaboration of the budget for 2014-2016 and that is focused on the stimulation of the economic growth modernization in the environment of the invigorating government policy on the improvement of the investment climate and growing efficiency of budget expenditures. Variant (2) based on the fulfillment of the measures reflected in the government programs on the development of the education, health care, science and technology, transportation infrastructure as well as the traditional sector of the economy implies additional financing.

Basing on the existing dynamics in January-April 2013 the attainment of the target indices of the forecast involves the turn of the negative trends in the industry and the recovery of the investment and the external demand in Q2 2103.

According to variant 2 the expected growth of the GDP in 2013 is $102.4 \%$, investments in fixed assets $-104.6 \%$, retail trade turnover $-104.3 \%$ versus the previous year. In 2013 it is forecast that the export slows down to $95.6 \%$ versus the figure of 2012 , import growing by $5.7 \%$. The forecast growth of the industrial production in 2013 is estimated to be $102.0 \%$. The minerals extraction stabilizing at the level of the previous year, the increase in manufacturing industries will make $2.9 \%$. Thus, the dynamics of the internal market given the forecast investment and consumer demand growth rates in 2013 will be formed in the environment of the anticipating growth of the import compared to the domestic production.

According to the forecast the growth rates of the real wages will slow down from $108.4 \%$ in 2012 to $104.5 \%$ in 2013 (103.7\% in the previous version of the forecast) which is due to the effect of high base, caused by the growth in the wages in the budget sector throughout 2012 . The growth rates of the real disposable incomes of the population was lowered to $3 \%$ in 2013 (3.7\% in the previous version of the forecast), which is due to the increase in the liabilities of the population connected with the interest payment for the received credits. Real wages will be maintained by the general decrease in the level of inflation from 7.1\% in Q1 2013 to 6.0-6.5\% in H2 2013.

Throughout the decade before 2009 crisis, the growth rates of the Russian economy made on average $7 \%$ annually, mainly due to the increase in the aggregated factor efficiency of labor and the level of facilities load.

In 2013 it is forecast that the trend for the anticipating growth of wages versus the dynamics of the labor efficiency will be maintained (102,5\%). The ratio of these two indices is influenced by the complex situation at the labor market: the demand exceeds the offer, the number of vacant

1 According to the conservative variant (1) the inertial process of the H1 2013 are to be maintained and the budget policy is to become stricter; the GDP growth rates will slow down to $101.7 \%$. The accelerated variant (3) is characterized by the GDP growth rates at the level of $103.2 \%$, investments in fixed assets growth rates - 106.5\%; the structural transformations are based on the considerable increase in private capital accumulation and renewal of the net capital inflow. The additional variants differ by the prices for oil: variant A assumes the worsening of the situation in the world economy and the decrease in the oil prices down to $\$ 90$ per barrel; variant $\mathrm{C}$ - maintenance of the oil prices in 2013 at the level of 2012, the price increasing to $\$ 120$ per barrel by 2016 . 
positions declared to the employment agencies is growing, and the substitution coefficient is rising. Despite the slowdown of the economic growth rates, the unemployment does not cease to lower. In April 2013 the unemployment made $4.2 \mathrm{~m}$ or $5.6 \%$ of the economically active population (based on the ILO methodology). Taking into account the existing trends at the labor market, the level of the unemployment by the end of the year will remain at the same level, the number of the employed being $67.7 \mathrm{~m}$. 